\section{Coral polyp expulsion}

In coral reef environments that suffer regular physical disturbances, the fragmentation of established colonies is believed to be important in the recruitment (recolonization) of the local area by branching and free-living corals ${ }^{1-4}$. High rates of wave action and sedimentation, for example, would favour fragmentation over the settlement and metamorphosis of sexually produced larvae ${ }^{1}$. Nonetheless, massive and encrusting coral species, which are abun-

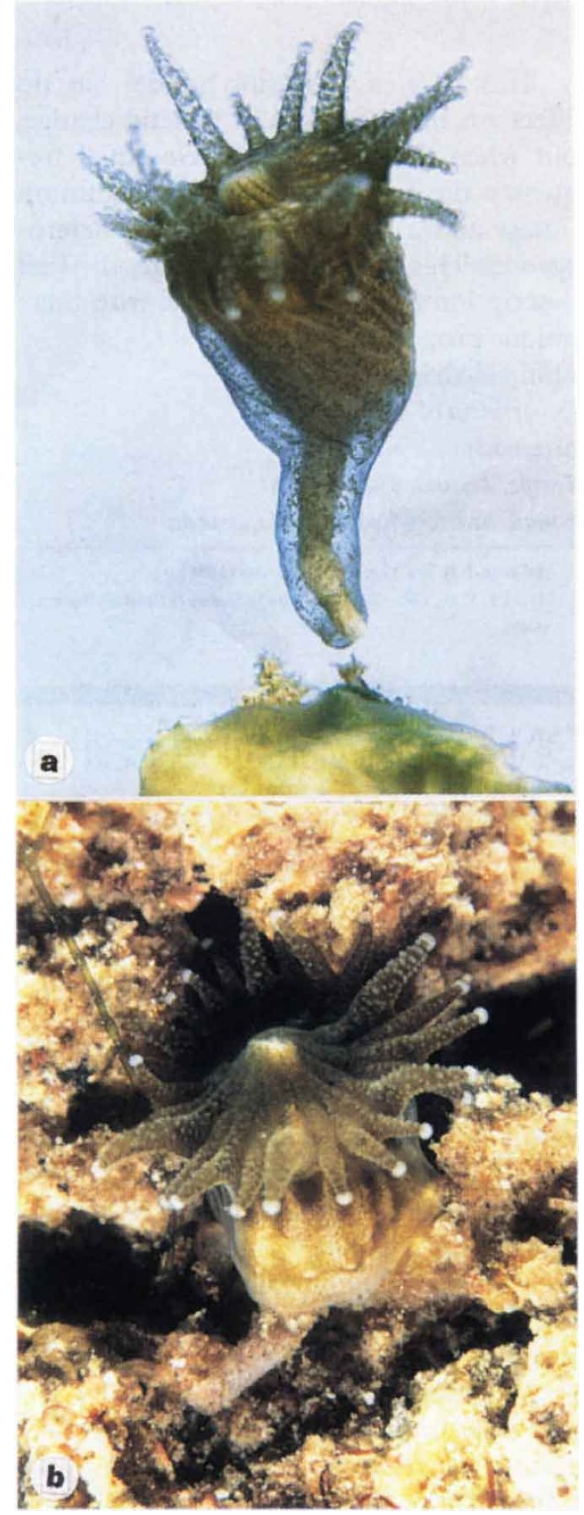

Figure 1 Polyp expulsion in the encrusting coral Oculina patagonica. a, An expelled polyp at the time of release. The tissue covering the calcareous stalk is visible $(\times 6.5)$. b, A newly settled expelled polyp, with tissues beginning to spread over the stalk and eventually over the substrate $(\times 6.0)$. The prevalence of expulsion was recorded along 10-m line transects ${ }^{8}$. Expulsion was observed in 34 of the 178 colonies of shallow-water O. patagonica recorded in 12 transects. All photographs by A. Shoob. dant in sandy shallow tropical waters, show only minimal fragmentation ${ }^{1}$. Here we report a mode of asexual reproduction in massive and encrusting corals, which enables them to sustain local populations in physically disturbed environments.

We have observed an unusual form of budding in massive and encrusting corals from shallow waters, particularly in Favia favus from the northern Red Sea and in Oculina patagonica from the Mediterranean coast of Israel. Individual polyps, including their calices, lift on elongated calcareous stalks (Fig. 1a) before detaching and settling elsewhere. The area of polyp expulsion (Fig. 2) regenerates within two weeks. The new propagule settles, its tissues spread over the stalk and onto the substrate (Fig. 1b), and the polyp forms a new colony through budding. In the laboratory, newly settled propagules of $O$. patagonica and $F$. favus developed and grew into new colonies within two months.

We also observed polyp expulsion in situ,

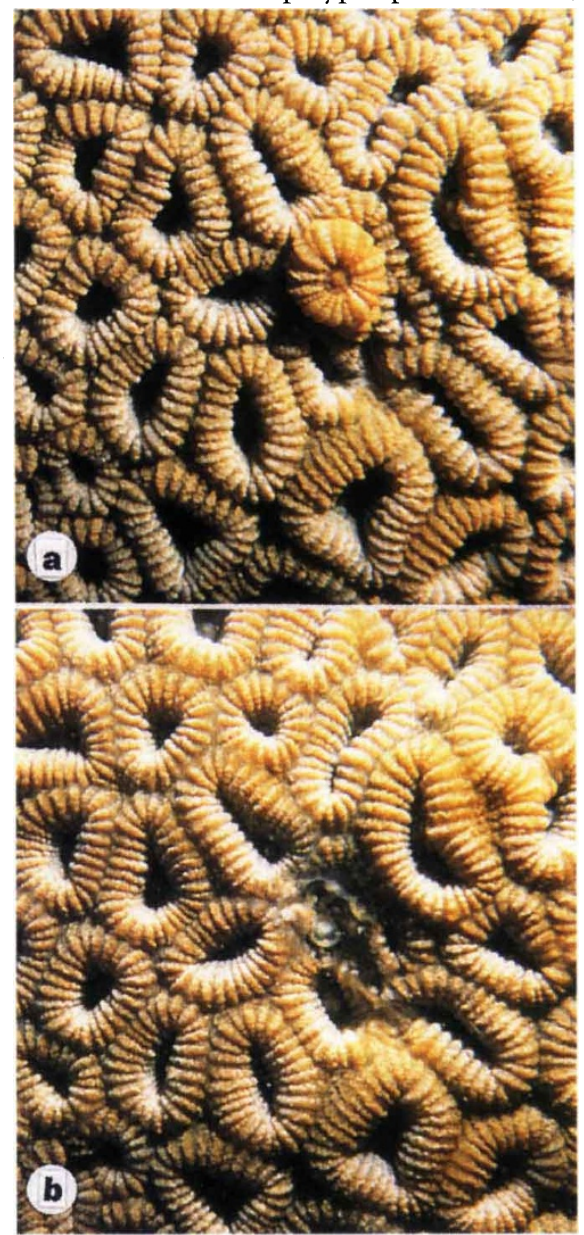

Figure 2 The massive coral Favia favus. a, An elevated polyp before expulsion; and $\mathbf{b}$, the area of detachment immediately after expulsion $(\times 0.6)$. Expulsion was seen in 10 of the $25 F$. favus colonies recorded in nine transects. in areas that suffered chronic levels of sedimentation, during the summer and autumn months when the water temperatures are highest $\left(26^{\circ} \mathrm{C}\right.$ in Eilat and $29^{\circ} \mathrm{C}$ in the Mediterranean). We did not see polyp expulsion in specimens from waters deeper than $4 \mathrm{~m}$ in the Red Sea and $7 \mathrm{~m}$ in the Mediterranean, indicating that this phenomenon might be unique to shallow water, where physical disturbances are more pronounced.

Histological sections revealed that during the peak reproductive season, polyps that were about to be expelled from the 'mother' colony contained no gonads, whereas surrounding polyps did. It is thus possible that the expelled polyp concentrates its stem-cell pool and energetic resources for use in reattachment and growth rather than for reproduction. Polyp expulsion may increase the survival rate of the parental genotype in a disturbed environment by ensuring that genotypically identical offspring are present at different stages in their life cycle ${ }^{5}$.

This phenomenon differs from the polyp 'bail-out' process, found in several branching pocilloporid coral species ${ }^{6,7}$. In polyp bailout, disintegrating corals release whole polyps from their calices, some with planulae, and the parent colony dies. In contrast, polyp expulsion occurs in physiologically healthy corals, and whole polyps, including their calices, are expelled. Unlike fragmentation, this process seems to be regulated by the colony and therefore may be considered a form of asexual reproduction.

As the main mode of reproduction in stony corals is sexual ${ }^{2}$, the question arises as to how successful recruitment ${ }^{1}$ occurs in chronically disturbed environments, where gametes and planulae may be swept away, dislodged or smothered by sediment. Our findings show that massive and encrusting stony corals which are abundant in such environments may overcome the difficulties of planular recruitment by reproducing asexually by polyp expulsion. As expelled polyps are larger than sexually derived propagules, they begin their sessile lives at the juvenile stage, avoiding the rigours of larval development, settlement and metamorphosis. This may be a form of size refuge, increasing the corals' chance of survival in disturbed environments.

E. Kramarsky-Winter, M. Fine, Y. Loya Department of Zoology,

Tel Aviv University, Tel Aviv 69978, Israel e-mail:yosiloya@ccsg.tau.ac.il

\footnotetext{
Highsmith, R. Mar. Ecol. Prog. Ser. 7, 207-226 (1982)

2. Harrison, P. L. \& Wallace, C. C. in Ecosystems of the World 25: Coral Reefs (ed. Dubinski, Z.) 133-206 (Elsevier, Amstersdam, 1990).

Scheer, G. Naturwiss. Ver. Darmstadt Ber. 1958/59, 50-60 (1959).

4. Rosen, B. R. \& Taylor, J. D. Science 166, 119-121 (1969).

5. Orive, M. E. Am. Nat. 145, 90-108 (1995).

6. Sammarco, P. W. Mar. Ecol. Prog. Ser. 10, 57-65 (1982).

Richmond, R. H. Mar. Ecol. Prog. Ser. 22, 181-185 (1985).

8. Loya, Y. Mar. Biol. 13, 100-123 (1972).
} 